\title{
Drug treatment of type 2 diabetes mellitus in patients for whom metformin is contraindicated
}

This article was published in the following Dove Press journal:

Diabetes, Metabolic Syndrome and Obesity: Targets and Therapy

18 January 2014

Number of times this article has been viewed

\author{
Brian K Irons' \\ Molly G Minze ${ }^{2}$ \\ 'Department of Pharmacy Practice, \\ Texas Tech University Health Sciences \\ Center School of Pharmacy, Lubbock, \\ ${ }^{2}$ Department of Pharmacy Practice, \\ Texas Tech University Health Sciences \\ Center School of Pharmacy, Abilene, \\ TX, USA
}

Correspondence: Brian K Irons Texas Tech University Health Sciences Center 360I 4th St, Lubbock, TX 79430, USA

Tel + I 8067434200

Fax +I 8067434209

Email brian.irons@ttuhsc.edu

\begin{abstract}
Metformin is considered an initial drug of choice for type 2 diabetes mellitus by leading recommendations. When contraindications to its use exist or patients cannot tolerate it due to adverse effects, clinicians have a variety of other classes of agents to treat hyperglycemia associated with type 2 diabetes mellitus. Each class of agent has its own benefit and safety profile. There are numerous factors to consider when selecting another agent in lieu of metformin including, but not limited to, overall efficacy in $\mathrm{A}_{1 \mathrm{c}}$ reduction, adverse effect profile, cost, and patient preference. The number of factors influencing the decision process presents challenges and often no one specific agent is ideal. Each pharmacotherapeutic class of agents alternative to metformin for the treatment of hyperglycemia in type 2 diabetes mellitus as initial monotherapy is reviewed.
\end{abstract}

Keywords: type 2 diabetes mellitus, metformin, monotherapy, hyperglycemia, pharmacotherapy

\section{Introduction}

Metformin has long been considered the initial drug therapy choice in the treatment of type 2 diabetes mellitus (T2DM). The most widely recognized clinical guidelines and consensus recommendations endorse its use when monotherapy is initially preferred to treat hyperglycemia. ${ }^{1-4}$ However, treatment with metformin is not suitable for all patients diagnosed with T2DM. Patients may initially receive metformin but not be able to tolerate common side effects, mainly its gastrointestinal adverse effects. Likewise, some practitioners may be cautious in using metformin in patients at risk for but who do not necessarily currently have specific contraindications to its use. While the specific contraindications to use of metformin have changed to an extent over the last decade, significant renal impairment or conditions that could acutely alter renal function remain a consistent theme in delineating who should not receive the medication. Some of the common sources and specific contraindications to the use of metformin based on renal function are provided in Table 1. Inconsistencies between these sources remain.

Current guidelines/consensus recommendations for specific therapies to initiate in patients who cannot tolerate or have a contraindication to metformin use provide some insight on the issue but also conflict with each other. The American Diabetes Association/European Association for the Study of Diabetes recommend a sulfonylurea, meglitinide, pioglitazone, or dipeptidyl peptidase 4 (DPP-4) inhibitor when metformin cannot be used. ${ }^{3}$ They also recommend using a glucagon-like peptide-1 (GLP-1) agonist if weight loss is warranted. The American Association of Clinical 
Table I Recommended precautions for and contraindications to use of metformin based on renal function

\begin{tabular}{|c|c|}
\hline Source & Renal criteria \\
\hline American Association & Review use with eGFR 30-44 \\
\hline of Clinical Endocrinology ${ }^{4}$ & Discontinue use with eGFR $<30$ \\
\hline National Institute for Health & Review dosage with eGFR $<45$ \\
\hline and Clinical Excellence ${ }^{2}$ & Discontinue use with eGFR $<30$ \\
\hline International Diabetes & Use with caution if eGFR $<45$ \\
\hline \multicolumn{2}{|l|}{ Federation' } \\
\hline FDA-approved drug label ${ }^{71}$ & $\begin{array}{l}\text { Contraindicated with serum } \\
\text { creatinine } \geq 133 \mathrm{mmol} / \mathrm{L}(1.5 \mathrm{mg} / \mathrm{dL}) \text { in } \\
\text { men, I } 24 \mathrm{mmol} / \mathrm{L}(1.4 \mathrm{mg} / \mathrm{dL}) \text { in women, } \\
\text { or with "abnormal creatinine clearance" }\end{array}$ \\
\hline UK MHRA ${ }^{72}$ & $\begin{array}{l}\text { Contraindicated with creatinine } \\
\text { clearance }<60 \mathrm{~mL} \text { per minute }\end{array}$ \\
\hline
\end{tabular}

Abbreviations: eGFR, estimated glomerular filtration rate (in $\mathrm{mL} / \mathrm{min} / 1.73 \mathrm{~m}^{2}$ ); FDA, US Food and Drug Administration; MHRA, Medicines and Healthcare Products Regulatory Agency.

Endocrinologists state GLP-1 agonists, DPP-4 inhibitors, and alpha-glucosidase inhibitors are acceptable alternatives to metformin. ${ }^{4}$ They recommend caution due to adverse effects in the use of thiazolidinediones, sulfonylureas, and meglitinides. The International Diabetes Federation recommends a sulfonylurea, meglitinide, or glucosidase inhibitor when metformin cannot be used. ${ }^{1}$

The following is a summary of the benefits and potential risks of using alternative diabetes agents in lieu of metformin for the treatment of T2DM and is intended to provide clinicians with practical information allowing them to make informed decisions in treating their patients. The review is limited to agents used as monotherapy. The primary considerations in selecting an alternative agent to metformin are listed in Table 2. Selection of which specific agent to initially employ to combat hyperglycemia should be individualized to a specific patient's therapeutic needs and personal wishes. The number of variables that need to be taken into consideration make decisions multifactorial and difficult; thus, clinicians are forced to weigh the benefits and risks of the various available agents. All agents carry a degree of risk,

Table 2 Factors to consider in selection of a diabetes agent

Baseline $A_{l c}$

Hyperglycemic issue (fasting, post-prandial, both)

Existing comorbidities

Risk of hypoglycemic complications

Injection preference

Adverse effect profile

Patient preference

Cost

Pleiotropic effects (eg, lipids, blood pressure)

Effect on pathophysiology of type 2 diabetes mellitus

Necessity for weight loss primarily in adverse effect profile, as well as benefit, based on effects on glycemic control and potential pleiotropic effects. In many patients, the benefits and risks are at odds with each other, as it may appear that one agent would provide more benefit but may also carry larger risks.

\section{Insulin secretagogues}

Insulin secretagogues, including the sulfonylureas and meglitinides, have been used consistently as monotherapy for the treatment of T2DM. Sulfonylureas, including glyburide, gliclazide, glipizide, and glimepiride or their predecessors have been used for the treatment of T2DM since the 1960s. ${ }^{5}$ The glucose-lowering effect of sulfonylureas is achieved by stimulation of insulin release from beta-cells within the pancreas and focuses primarily upon fasting blood glucose reduction although has some effects on post-prandial glucose as well., ${ }^{5,6}$ The meglitinide class of medications include nateglinide and repaglinide, both of which are rapid-acting insulinotropic agents that allow insulin release from beta-cells within the pancreas in a glucose-dependent manner, thus focusing on post-prandial glucose reduction. ${ }^{5,7}$ These agents are quite effective and can produce a $1 \%-2 \%$ decrease in $\mathrm{A}_{1 \mathrm{c}}{ }^{5}$

Given their focus upon increasing insulin secretion from pancreatic beta-cells, a function that is already impaired or dysfunctional in T2DM, neither of these classes of agents promote protective effects towards or conserve pancreatic beta-cells, and in contrast sulfonylureas promote progressive deterioration in glycemic control over time and do not have protective effects against atherosclerotic complications. ${ }^{8}$ After initial $\mathrm{A}_{1 \mathrm{c}}$ decline, patients treated with a sulfonylurea alone have an increase in $\mathrm{A}_{1 \mathrm{c}}$ after 1.5 years, and monotherapy fails in $34 \%$ of patients at 5 years. ${ }^{8} 9$ However, clinical trial data with sulfonylureas have shown a reduction in microvascular complications in the first 10 years of diagnosis when sulfonylureas were used to lower $\mathrm{A}_{1 \mathrm{c}}$ to an average of $7 \%{ }^{10}$ The cost of sulfonylureas is low, whereas the cost of meglitinides is higher. ${ }^{3,5}$

The risk most associated with sulfonylureas and meglitinides is hypoglycemia. ${ }^{3,5,9}$ Longer-acting sulfonylureas such as glyburide carry a higher risk of hypoglycemia than shorteracting sulfonylureas, and meglitinides have less hypoglycemia than sulfonylureas secondary to their shorter half-life., ${ }^{3,6,11}$ Weight gain is an additional limitation of sulfonylureas and meglitinides, averaging 1-4 kg gain with sulfonylureas and less with meglitinides. ${ }^{3,5}$ Concomitant use of warfarin, salicylates, sulfonamides, fibrates, and allopurinol can potentiate hypoglycemia with sulfonylurea use. ${ }^{5}$ Despite significant 
historical use, the cardiovascular safety of sulfonylureas has not proven beneficial, and even supports limited use in patients with significant cardiovascular disease. ${ }^{3,5}$

Sulfonylureas reduce fasting plasma glucose, whereas meglitinides reduce post-prandial glucose via stimulation of pancreatic beta-cells. Vast historical use showing early reductions in blood glucose and the low cost of sulfonylureas continue to make them a popular choice for monotherapy. Currently, the American Diabetes Association/European Association for the Study of Diabetes supports the use of sulfonylureas as a first-line option in patients who cannot receive metformin therapy, particularly if cost is a barrier to adequate therapy. ${ }^{3}$ Meglitinides are recommended for use in patients with erratic meal schedules or who have late post-prandial glycemia when they use sulfonylureas, or can be used in place of sulfonylureas. ${ }^{3}$ If metformin is contraindicated due to poor renal function, glyburide may not be an optimal choice because the risk of hypoglycemia is increased due to the agent and its active metabolites not being sufficiently cleared compared with patients having normal renal function. The meglitinides do not undergo extensive renal clearance and are a good option in this case.

\section{GLP-I receptor agonists}

GLP-1 receptor agonists are exogenous analogs promoting the incretin effect that is normally diminished in a patient with T2DM. ${ }^{12}$ These analogs activate the GLP-1 receptor to increase glucose-dependent insulin secretion and decrease glucagon secretion, slow gastric emptying, and increase satiety. ${ }^{3}$ In addition to lowering blood glucose, GLP-1 agonists also contribute to weight loss, promote beta-cell preservation, and may have a role in beta-cell regeneration. ${ }^{3,8}$ The available agents marketed are exenatide, available as a twice-daily or once-weekly injection, and liraglutide, available as a once-daily injection. ${ }^{12}$

During a 24-week monotherapy trial, patients with an $A_{1 c}$ between $6.5 \%$ and $10 \%$ and treated with only diet and exercise were prescribed exenatide $5 \mu \mathrm{g}$ or $10 \mu \mathrm{g}$ twice daily, which produced a significant $0.7 \%-0.9 \%$ decrease in $\mathrm{A}_{1 \mathrm{c}} \cdot{ }^{13}$ The exenatide treatment group had greater weight loss compared with the placebo group, being $-2.8 \mathrm{~kg},-3.1 \mathrm{~kg}$, and $-1.4 \mathrm{~kg}$ with the $5 \mu \mathrm{g}$ dose, $10 \mu \mathrm{g}$ dose, and placebo, respectively. Exenatide-treated patients had a greater reduction in blood pressure than the placebo group, but no difference in lipid markers was observed. When used as monotherapy in drug-naïve patients, exenatide once weekly also reduced $\mathrm{A}_{1 \mathrm{c}}$ more than sitagliptin alone and showed efficacy similar to that of metformin and pioglitazone monotherapies over a 26 -week time period. ${ }^{14}$ Once-weekly exenatide was also associated with weight losses similar to metformin, while patients receiving pioglitazone showed significant weight increases. Beta-cell function improved in the once-weekly exenatide group as compared with the other groups, whereas insulin sensitivity improved in the metformin and pioglitazone groups. The once-weekly formulation of exenatide shows modestly greater reductions in $\mathrm{A}_{1 \mathrm{c}}$ compared with the twice-daily formulation, and appears to reduce fasting and post-prandial glucose levels, while the twice-daily formulation appears to have a greater focus on post-prandial glucose levels. ${ }^{15}$

Liraglutide also has data supporting its use as monotherapy in drug-naïve patients with diabetes. During a 104week monotherapy trial, patients were randomized to receive liraglutide $1.2 \mathrm{mg}$, liraglutide $1.8 \mathrm{mg}$, or glimepiride $8 \mathrm{mg}$ daily. ${ }^{16}$ Liraglutide at both doses lowered $\mathrm{A}_{1 \mathrm{c}}$ significantly more than glimepiride $(-0.6 \%,-0.9 \%$ for liraglutide $1.2 \mathrm{mg}$ and $1.8 \mathrm{mg}$, respectively, versus $-0.3 \%$ for glimepiride). Additionally, weight loss was seen after 12 weeks of therapy and maintained after 104 weeks in both liraglutide groups, where the glimepiride group gained weight. Published head-to-head trials comparing exenatide and liraglutide are lacking.

Adverse effects most consistently observed with the GLP-1 analogs are gastrointestinal in nature, mainly nausea and vomiting. ${ }^{13,14,16}$ Hypoglycemia when exenatide or liraglutide is used as monotherapy is usually mild and occurs at a low frequency. The long-term safety and effects on cardiovascular events are still pending. Of concern, shortly after this class of agents first appeared on the market, were the case reports of pancreatitis. Large epidemiology studies do not support an increased risk for pancreatitis with the GLP-1 analogs compared with other diabetes agents. ${ }^{17,18}$ Whether GLP-1 analogs increase the risk for pancreatic or thyroid cancer remains unknown as well, but animal models suggest at least a theoretical risk although no conclusive evidence in humans is available. ${ }^{19}$

This class of medications is a viable option for patients intolerant to metformin. The lowering of $\mathrm{A}_{1 \mathrm{c}}$, weight loss, low hypoglycemia risk, beta-cell preservation, and neutral cardiovascular risk are benefits of exenatide and liraglutide therapy. GLP-1 agonists are recommended for use as monotherapy in patients who cannot tolerate metformin if weight loss is essential. ${ }^{3}$ However, if metformin is contraindicated due to significant renal impairment (creatinine clearance $<30 \mathrm{~mL}$ per minute) either exenatide formulation should be avoided. Use in patients with a history of pancreatitis should also 
be avoided. Disadvantages of this class of medications include cost and the nausea associated with therapy. Patients averse to having to self-inject these agents or unable to so due to cognitive or physical impairment would not be good candidates for therapy. Long-term surveillance data are needed to determine the overall risk these agents may pose.

\section{Sodium-glucose cotransporter-2 inhibitors}

In T2DM, the plasma glucose level at which renal reabsorption capacity is reached and glucosuria occurs is increased above the standard physiologic threshold, and contributes to worsening hyperglycemia. ${ }^{20-23}$ Sodium-glucose cotransporter-2 inhibitors (SGLT2-I) induce urinary glucose excretion by reducing renal glucose resorptive capacity within the proximal convoluted tubule, ultimately leading to reduced plasma glucose. ${ }^{24,25}$ This provides an insulinindependent mechanism for plasma glucose-lowering by inducing urinary glucose excretion through mild osmotic diuresis, causing increased caloric loss and weight loss. ${ }^{21,24}$ These agents may also delay absorption of glucose in the intestine, but this is a secondary and lesser mechanism of action. ${ }^{23}$ Currently, canagliflozin is approved in the US and Europe and dapagliflozin is approved in Europe but not approved in the US due to safety concerns. ${ }^{26}$

When used in drug-naïve patients inadequately controlled with diet and exercise alone, both agents have been shown to reduce $\mathrm{A}_{1 \mathrm{c}}$ by between $0.7 \%$ and $1.45 \%$ and to have positive effects on both fasting and post-prandial hyperglycemia. ${ }^{21,27}$ In patients with very elevated blood glucose (baseline $\mathrm{A}_{1 \mathrm{c}}$ $10.6 \%$ ), canagliflozin $100 \mathrm{mg}$ and $300 \mathrm{mg}$ reduced $\mathrm{A}_{1 \mathrm{c}}$ by $2.13 \%$ and $2.56 \%$, respectively, after 26 weeks of therapy. ${ }^{21}$ Canagliflozin has also been shown to reduce hyperglycemia in a Japanese population with T2DM, reducing $A_{1 c}$ by between $0.61 \%$ and $0.88 \% .^{22}$ The agents have also been shown to have positive effects on weight and may improve beta-cell function when used as monotherapy. ${ }^{21,27}$ However, long-term studies assessing preservation of beta-cell function are warranted. In addition, trials have shown some positive, albeit mild, effects on lipids and blood pressure, but to date have not been adequately evaluated as to any specific cardiovascular benefit.

SGLT2-I appear to be fairly well tolerated. Genital mycotic and urinary tract infections were higher in SGLT2-I-treated groups compared with placebo. Rates of hypoglycemia appear similar to placebo and no cases of severe hypoglycemia occurred in monotherapy studies. ${ }^{20,21,26}$ There has been some concern, stemming from early adverse event reports with dapagliflozin, that this class of medication may increase the risk for some cancers, particularly bladder cancer. Additional safety studies of both agents are underway to assess for any particular harm. Lastly, as the newest class of agent to treat T2DM, there are no generic alternatives and cost may be an issue for some patients or health care systems.

SGLT2-I provide a novel, insulin-independent mechanism for the treatment of T2DM that appears well tolerated by patients and results in little hypoglycemia. Once-daily oral administration may make them an attractive alternative to certain other antidiabetic agents for some patients. They perform well in reducing $\mathrm{A}_{1 \mathrm{c}}$ when compared with placebo; however, there are very few comparative data to adequately compare this class of agent when used as monotherapy with other available agents. Long-term cardiovascular and safety data are not yet available. If a patient cannot receive metformin due to significant renal impairment (creatinine clearance $<45 \mathrm{~mL}$ per minute), use of canagliflozin should also be avoided.

\section{DPP-4 inhibitors}

Over the past few years, there have been numerous DPP-4 inhibitors approved for use in the treatment of hyperglycemia associated with T2DM. The number of agents available differs depending on the country, but vildagliptin, sitagliptin, saxagliptin, alogliptin, and linagliptin are the most studied and readily available agents within this relatively new class of medications. Considered incretin-based therapy, DPP-4 inhibitors work to combat hyperglycemia by minimizing the metabolism of GLP-1 secreted after oral ingestion of carbohydrates and fat. The reduction in $\mathrm{A}_{1 \mathrm{c}}$ when these agents are used as monotherapy in drug-naive T2DM patients ranges from $0.4 \%$ and $1.1 \%$, and they appear to do a better job in reducing post-prandial blood glucose levels than fasting levels. ${ }^{14,28}$ The overall reduction in $\mathrm{A}_{1 \mathrm{c}}$ is less when compared with monotherapy of pioglitazone or extendedrelease exenatide. ${ }^{14}$ DPP-4 inhibitors have been shown to have a positive impact on beta-cell function but long-term studies on beta-cell preservation are lacking. These agents appear to be weight-neutral and to carry a very low risk for hypoglycemia. ${ }^{29,30}$ It is unknown if this class of agents has potential beneficial pleiotropic effects. They do not appear to have any beneficial cardiovascular effects. ${ }^{31}$

Although very well tolerated in clinical trials, there is some fear that these agents are associated with an increased risk of pancreatitis. The initial concern came primarily from isolated case reports early after the approval and use 
of sitagliptin in the marketplace. Patients with diabetes do have a higher risk of pancreatitis than patients without the disorder. ${ }^{32}$ However, meta-analyses and observational studies do not support an increased risk for pancreatitis with this class of agents over other medications used to treat diabetes. ${ }^{17,33}$ Further research into the risk these agents carry for pancreatitis is necessary.

Given the lack of comparative clinical trials between the agents in this class, it is too difficult to suggest one agent is any safer or efficacious than another. They can be considered in lieu of metformin in patients with modest hyperglycemia $\left(\mathrm{A}_{1 \mathrm{c}}<0.9 \%\right.$ above desired goal), when post-prandial hyperglycemia is a primary concern, when weight neutrality is warranted, and if the risks of hypoglycemia are of great concern. Cost is an issue given that none of the currently available agents exist in generic form. Until the pancreatitis issue is fully understood, clinicians should exercise caution when using these agents in patients with a history of or at great risk for pancreatitis. If significant renal impairment is the cause for not considering metformin monotherapy, each of the DPP-4 inhibitors can still be considered although with the exception of linagliptin, the dose of which needs to be reduced.

\section{Alpha-glucosidase inhibitors}

Alpha-glucosidase inhibitors are infrequently used in the treatment of T2DM. ${ }^{3}$ These agents competitively inhibit the absorption of alpha-glucosidase along the brush border of the small intestine, which slows gut absorption of carbohydrates and ultimately reduces post-prandial blood glucose. ${ }^{34-36}$ Overall, reduction in $\mathrm{A}_{1 \mathrm{c}}$ is limited to $0.5 \%-0.7 \%$. Three alpha-glucosidase inhibitors are approved for use, ie, acarbose, miglitol, and voglibose.

In patients inadequately controlled by diet and exercise or a sulfonylurea who had a baseline $\mathrm{A}_{1 \mathrm{c}}$ of $9.06 \%$, acarbose reduced $A_{1 c}$ by an average of $-0.66 \%$ and reduced post-prandial glucose levels by $41 \mathrm{mg} / \mathrm{dL} .{ }^{37}$ Evidence for using alpha-glucosidase inhibitors as monotherapy in the elderly population shows that miglitol, when dosed at $25 \mathrm{mg}$ and $50 \mathrm{mg}$ three times daily with meals, reduced $\mathrm{A}_{1 \mathrm{c}}$ by $0.41 \%-0.5 \%$ after one year, with a primary effect on post-prandial glucose concentrations. ${ }^{35}$ Hypoglycemia and discontinuation rates due to adverse effects occurred at a similar rate to that of placebo. In a very small trial of Japanese patients newly diagnosed with T2DM, voglibose $0.9 \mathrm{mg}$ daily reduced $\mathrm{A}_{1 \mathrm{c}}$ from $8 \%$ at baseline to $6.3 \%{ }^{38} \mathrm{In}$ an additional trial 12-week trial, voglibose dosed at $0.2 \mathrm{mg}$ three times daily reduced $\mathrm{A}_{1 \mathrm{c}}$ by an average of $0.3 \% .{ }^{39}$
The adverse effect profile and tolerability of alpha-glucosidase inhibitors is limited to their gastrointestinal tolerability; however, they do not cause weight gain and have a good safety record. ${ }^{5}$ Within the adult and elderly population, diarrhea and flatulence occurred more often in patients treated with acarbose, miglitol, or voglibose. ${ }^{35,37,39}$ Alpha-glucosidase inhibitors cause little to no hypoglycemia, and miglitol has been shown to reduce triglycerides. ${ }^{36}$ Alphaglucosidase inhibitors reduce post-prandial blood glucose and are associated with minimal hypoglycemia, but only marginally reduce $A_{1 c}$ and have significant gastrointestinal adverse effects. Doses are to be taken with each meal, and few monotherapy trials are available. Long-term cardiovascular safety data are favorable and dose adjustments are not needed in patients with renal insufficiency. ${ }^{36}$ Because of this, alpha-glucosidase inhibitors do represent a viable option for patients unable to take metformin secondary to renal impairment, particularly if the primary elevation in blood glucose occurs post-prandially and the $\mathrm{A}_{1 \mathrm{c}}$ is only mildly elevated.

\section{Colesevelam}

The bile acid sequestrant, colesevelam, used primarily for the treatment of dyslipidemia, has also been associated with improvements in glycemic control in patients with T2DM. The exact mechanism by which it has this effect is unknown. It is thought that the effects of this agent on farnesoid X receptors in the intestines and liver may be responsible for improvements in glucose concentrations. ${ }^{40}$ A recent study attempting to elucidate the mechanism of action of colesevelam found no effect on insulin action or secretion and no effect on GLP-1 concentrations. ${ }^{41}$ However, the rate of meal appearance as assessed by a radiolabeled standard meal was lowered, suggesting that perhaps splanchnic sequestration of meal-derived glucose may play a role in lowering glucose concentrations. To date, no longterm clinical trials in drug-naïve patients using colesevelam as monotherapy exist. The one small, short-term monotherapy study ( 35 patients, 8 weeks) that does exist actually showed a small increase in both $\mathrm{A}_{1 \mathrm{c}}$ and fructosamine in patients receiving colesevelam. ${ }^{42}$ Data from clinical trials using colesevelam as add-on therapy to other glucose-lowering agents suggest that this agent provides only mild reductions in $\mathrm{A}_{1 \mathrm{c}}(0.3 \%-0.4 \%)$ and improves both fasting and post-prandial glucose concentrations. ${ }^{43-45}$ The degree of $\mathrm{A}_{1 \mathrm{c}}$ reduction appeared to be significantly less than with rosiglitazone, a thiazolidinedione, although similar to sitagliptin, a DPP-4 inhibitor, in a comparative study of patients receiving metformin. ${ }^{45}$ There are no data to suggest that the agent has a significant effect on insulin resistance or preservation of beta-cell function. As expected, colesevelam 
did show a reduction in low-density lipoprotein cholesterol $(12 \%-16 \%)$.

Colesevelam is not widely available as a generic medication and is more expensive than the generic agents used to treat T2DM. Colesevelam has a low risk of hypoglycemia. The most common adverse reaction is constipation. There does not appear to be any significant adverse event associated with the agent in trials up to 52 weeks in duration. ${ }^{46,47}$

Given the lack of clinical monotherapy data, it is difficult to determine whether colesevelam may be considered as monotherapy in a patient who cannot tolerate or receive metformin. It may be considered in patients with an only mildly elevated baseline $\mathrm{A}_{1 \mathrm{c}}(<0.5 \%$ above goal $)$ and when additional low-density lipoprotein cholesterol reduction is warranted, although the agent should not replace statin therapy if tolerated, given that there are no clinical trials demonstrating a reduction in cardiovascular outcomes in patients with diabetes receiving colesevelam. This agent should be avoided in patients who have difficulty swallowing because the pill size is rather large. It should be avoided in patients with markedly elevated serum triglyceride concentrations or a history of hypertriglyceridemia-induced pancreatitis.

\section{Bromocriptine}

Bromocriptine, a dopamine- 2 receptor agonist historically used for the treatment of Parkinson's disease, has now been approved in a rapid-release formulation for the treatment of hyperglycemia associated with T2DM. ${ }^{48}$ While the exact mechanism of action is unknown, it is thought to reduce post-prandial blood glucose and hepatic glucose production through augmentation of low hypothalamic dopamine levels and inhibition of excess sympathetic tone in the central nervous system through inhibition of serotonin turnover. ${ }^{49,50}$ Further using the theory that seasonal changes promote circadian neuroendocrine rhythms that play a role in insulin sensitivity and changes in body fat stores for preparation of hibernation or winter, dopaminergic and serotonergic activity is thought to contribute to this cycle and accompany insulin resistance. ${ }^{50}$ By delivering exogenous bromocriptine in the morning, a circadian resetting is thought to occur within the dopamine signals and produce a neurochemistry similar to a nondiabetic state. ${ }^{51}$ There is only a handful of trials available that assess bromocriptine in the treatment of T2DM and there are no trials that use bromocriptine as monotherapy in drugnaïve patients. From the data available, bromocriptine elicits an approximately $0.1 \%-0.6 \%$ decrease in $A_{1 c}$ and appears to affect both fasting and post-prandial glucose levels. ${ }^{48,52}$ A short-term safety trial found that bromocriptine lowered the relative risk of cardiovascular outcomes by $39 \%$ after one year of therapy compared with placebo, despite having little or no effect on lipids or blood pressure. ${ }^{53,54}$

Safety data show that nausea, headache, vomiting, somnolence, and hypoesthesia are reported more frequently in bromocriptine-treated patients than with placebo. ${ }^{53}$ The rate of hypoglycemia with bromocriptine was reported at $6.9 \%$ versus $5.3 \%$ with placebo.

Bromocriptine provides only modest reductions in blood glucose and $\mathrm{A}_{1 \mathrm{c}}$, but does not elicit frequent hypoglycemia and may have a short-term positive cardiovascular profile. The lack of data using the agent in drug-naïve patients, in patients with significant renal insufficiency, or data that can be compared with other diabetes medications makes decisionmaking regarding its place in therapy difficult. There are no data regarding its efficacy or safety beyond 52 weeks of therapy. The rapid-release formulation is only marketed and available for use as an antihyperglycemic in the US. If used, the product should be administered with food and within 2 hours of waking. ${ }^{52}$

\section{Insulin}

The choice of different insulins based on duration or onset of activity has significantly increased over the past 12 years. The literature focused on insulin therapy in the treatment of T2DM during this time has focused mainly on adding insulin therapies to oral diabetes medications, and the volume of studies using insulin as monotherapy is small. Leading guidelines suggest that insulin should be used when patients present with significantly elevated hyperglycemia (eg, $\mathrm{A}_{1 \mathrm{c}}$ more than $9 \%-10 \%$ ) particularly if showing signs and symptoms of hyperglycemia. ${ }^{3,4}$ Treatment with oral agents, particularly when used as monotherapy, is not likely to provide a sufficient reduction in glucose concentrations when $A_{1 c}$ is markedly elevated. Given the variety of insulins available and the numerous ways in which they can be employed to treat patients with T2DM, it is beyond the scope of this review to adequately examine the various possible insulin treatment strategies, but this topic has been appropriately reviewed elsewhere. ${ }^{55}$ The ability of insulin to lower hyperglycemia in patients with T2DM is stronger than with oral agents, because insulin can be sufficiently titrated to target specific glycemic goals, whether fasting or post-prandial, whereas oral agents are limited in their dosing strategies and maximum daily dosage. How great a decrease in $\mathrm{A}_{1 \mathrm{c}}$ one can obtain with insulin therapy is very dependent on a patient's baseline $A_{1 c}$, and insulin monotherapy has been shown to decrease $A_{1 c}$ in T2DM by $1.3 \%-5.2 \% .^{56,57}$ 
Selection of insulin allows a clinician to focus on either fasting or post-prandial hyperglycemia, or both, depending on a specific patient's therapeutic needs. If fasting glucose concentrations are the only glycemic problem, use of a once-daily or twice-daily basal insulin should suffice. However, if post-prandial glucose excursions in addition to increased fasting glucose occur together, a combination of basal and bolus insulin or a fixed insulin combination is warranted. Early short-term use of insulin monotherapy in patients with newly diagnosed T2DM and significant hyperglycemia $\left(\mathrm{A}_{1 \mathrm{c}} 10 \%-11 \%\right)$ has been shown to dramatically improve hyperglycemia, improve beta-cell function, and in some cases maintain euglycemia for extended periods after discontinuation of insulin. ${ }^{57-59}$ There does not appear to be a cardiovascular benefit to insulin monotherapy in the treatment of T2DM. Costs associated with care are dependent on which agent or agents are chosen, considering that newer, physiologic insulins are more expensive compared with older short-acting or intermediate-acting insulins.

While excellent at controlling hyperglycemia, insulin therapy also carries risks. Hypoglycemia and weight gain are the more common adverse effects associated with insulin use. Injection site pain or infection is also possible. Some patients may be averse to the notion of self-injection or may not have the physical or cognitive capacity to safely inject insulin. More recently, epidemiologic evidence suggests that insulin monotherapy is associated with worse outcomes in the form of increased mortality, cancer, and diabetes-related complications compared with commonly used oral agents. ${ }^{60}$ In addition, insulin elimination is slowed in patients with renal dysfunction, so caution should be exercised if insulin is used as an alternative to metformin secondary to renal insufficiency. ${ }^{3}$

When the risks of increased weight or hypoglycemia do not outweigh the need for significant improvement in hyperglycemia, insulin monotherapy is a potent option in the treatment of T2DM. The variety of available insulins allow for individualized dosing strategies based on glycemic need. In cases of mild to moderate hyperglycemia (eg, $\mathrm{A}_{\mathrm{lc}}<9 \%$ ), insulin monotherapy may not provide any benefit over other diabetes agents, but nonetheless remains the most effective class of agents to control hyperglycemia.

\section{Thiazolidinediones}

Given the elimination of rosiglitazone in some countries and significant limitations to its use in others in recent years due to safety concerns, the only viable agent in this class to consider is pioglitazone. Thiazolidinediones have various effects that help to control hyperglycemia, but their primary mechanism of action is to improve insulin sensitivity and they remain the best class of diabetes medication for combating insulin resistance, a main contributor to the development of hyperglycemia in T2DM. ${ }^{8,61}$ Pioglitazone exerts it effects on insulin resistance by stimulating peroxisome proliferatoractivated receptor gamma, thus altering key transcription genes responsible for carbohydrate and lipid metabolism. ${ }^{3,62}$ In drug-naïve patients, monotherapy with pioglitazone achieves significant reductions in $\mathrm{A}_{1 \mathrm{c}}(1.3 \%-1.6 \%)$, improves both fasting and post-prandial glucose concentrations, and has a very low risk of hypoglycemia. ${ }^{14,62-64}$ Clinical trial data suggest that pioglitazone provides a reduction in $A_{10}$ similar to that of extended-release exenatide and provides for better $\mathrm{A}_{1 \mathrm{c}}$ reductions compared with a DPP-4 inhibitor. ${ }^{14}$ Thiazolidinediones as monotherapy have also been shown to provide more sustained glycemic control compared with sulfonylureas. ${ }^{9,65}$ Thiazolidinediones also improve or at least preserve pancreatic beta-cell function in T2DM. In addition to these benefits, pioglitazone has demonstrated some degree of secondary cardiovascular prevention in patients with established cardiovascular disease and has been shown to improve high-density lipoprotein cholesterol and reduce triglyceride concentrations in patients with T2DM. ${ }^{61,66}$ Pioglitazone is also widely available as a generic medication and is less expensive than some of the newer agents used to treat T2DM.

Thiazolidinediones have limitations due to their adverse effect profile. Weight gain and peripheral edema are common with these agents. More concerning, although occurring at a significantly lower rate, is the potential for thiazolidinediones to cause heart failure, macular edema, and bladder cancer. They may also increase the risk for peripheral bone fractures. The risk for bone fractures is higher in women than in men, but is evident in both genders. ${ }^{67}$ The risk for developing macular edema with thiazolidinediones is small and based on observational studies. ${ }^{68}$ So too is the potential risk of developing bladder cancer, that appears to be dose-dependent and increases with longer use of thiazolidinedione therapy. ${ }^{69}$

Based on the benefit-to-risk profile of pioglitazone, some clinical experts remain adamant that this agent still has a role in the treatment of T2DM. ${ }^{61,70}$ However, some countries, eg, France and Germany, have suspended its marketing and its use in many other countries is limited.

Further research as to the serious adverse events possible with pioglitazone continues. Where it remains available, pioglitazone can be considered as monotherapy in patients who cannot tolerate or receive metformin when their baseline $\mathrm{A}_{1 \mathrm{c}}$ is roughly $1.5 \%$ or less above their goal, in patients 
at significant risk for repercussions from hypoglycemia (eg, those with established cardiovascular disease), and in patients where insulin resistance is strongly suspected as a significant contributor to hyperglycemia (eg, those with signs of metabolic syndrome). ${ }^{61}$ It can be used safely in patients with significant renal impairment if that were the contraindication for metformin use. Pioglitazone should be avoided in patients with moderate to severe heart failure and in those with existing or at high risk for bladder cancer. It should be used cautiously in patients with existing low bone mineral density.

\section{Conclusion}

Clinicians now have a range of effective agents to choose from when treating T2DM hyperglycemia. While metformin remains the initial treatment of choice, the alternatives in cases of intolerance or contraindication are many. However, clinicians and patients are faced with no one ideal agent to use in lieu of metformin and multiple factors to consider in determining the most appropriate therapy choice for a specific patient. These factors may conflict with each other. A sulfonylurea may be a viable option for a patient due to its low cost and significant $\mathrm{A}_{1 \mathrm{c}}$-lowering capabilities. However, its higher risk for hypoglycemia and weight gain compared with other agents may have serious consequences for some patients. A GLP-1 agonist may provide significant necessary reductions in $\mathrm{A}_{1 \mathrm{c}}$ and weight, but may be an undue financial burden to a patient or health care system or cause significant nausea. As described above, there are risks and benefits to any decision. Clinicians and patients must weigh these and ultimately select the agent with most benefit and least risk, all the while maintaining and keeping in mind the end goal of euglycemia without diabetes-related complications.

\section{Disclosure}

The authors report no conflicts of interest in this work.

\section{References}

1. International Diabetes Federation. Global guideline for type 2 diabetes. Available from: http://www.idf.org/global-guideline-type-2-diabetes2012. Accessed September 5, 2013.

2. National Institute for Health and Clinical Excellence. Type 2 diabetes: The management of type 2 diabetes (NICE clinical guideline 87). Available from: http://www.nice.org.uk/guidance/CG87. Accessed August 15, 2013.

3. Inzucchi SE, Bergenstal RM, Buse JB, et al. Management of hyperglycemia in type 2 diabetes: a patient-centered approach. Diabetes Care. 2012;35:1364-1379.

4. Garber AJ, Abrahamson MJ, Barzilay JI, et al. American Association of Clinical Endocrinologists' comprehensive diabetes management algorithm 2013 consensus statement. Endocr Pract. 2013;19 Suppl 2: $1-48$.
5. Krentz AJ, Bailey CJ. Oral antidiabetic agents: current role in type 2 diabetes mellitus. Drugs. 2005;65:385-411.

6. Melander A. Kinetics-effect relations of insulin-releasing drugs in patients with type 2 diabetes. Diabetes. 2004;53 Suppl 3:S151-S155.

7. Carroll MF, Izard A, Riboni K, Burge MR, Schade DS. Control of postprandial hyperglycemia. Diabetes Care. 2002;25:2147-2152.

8. Defronzo RA. From the triumvirate to the ominous octet: a new paradigm for the treatment of type 2 diabetes mellitus. Diabetes. 2009;58:773-795.

9. Kahn S, Haffner S, Heise M, et al. Glycemic durability of rosiglitazone, metformin, or glyburide monotherapy. N Engl J Med. 2006;355: $2427-2443$

10. Turner RC, Holman RR, Cull CA, et al; UK Prospective Diabetes Study (UKPDS) Group. Intensive blood-glucose control with sulfonylureas or insulin compared with conventional treatment and risk of complications in patients with type 2 diabetes (UKPDS 33). Lancet. 1998;352: 837-853.

11. Rosenstock J, Hassman DR, Madder RD, et al. Repaglinide versus nateglinide monotherapy. Diabetes Care. 2004;27:1265-1270.

12. Gallwitz B. Glucagon-like peptide-1 analogues for type 2 diabetes mellitus: current and emerging agents. Drugs. 2011;71: $1675-1688$

13. Moretto TJ, Milton DR, Ridge TD, et al. Efficacy and tolerability of exenatide monotherapy over 24 weeks in antidiabetic drug-naïve patients with type 2 diabetes: a randomized, double-blind, placebocontrolled, parallel-group study. Clin Ther. 2008;30:1448-1460.

14. Russell-Jones D, Cuddihy RM, Hanefeld M, et al. Efficacy and safety of exenatide once weekly versus metformin, pioglitazone, and sitagliptin used as monotherapy in drug-naïve patients with type 2 diabetes (DURATION-4). Diabetes Care. 2012;35:252-258.

15. Blevins T, Pullman J, Malloy J, et al. DURATION-5: Exenatide once weekly resulted in greater improvements in glycemic control compared with exenatide twice daily in patients with type 2 diabetes. $J$ Clin Endocrinol Metab. 2011;96:1301-1310.

16. Garber A, Henry RR, Ratner R, Hale P, Chang CT, Bode B; LEAD-3 (Mono) Study Group. Liraglutide, a once-daily human glucagon-like peptide 1 analogue, provides sustained improvements in glycaemic control and weight for 2 years as monotherapy compared with glimepiride in patients with type 2 diabetes. Diabetes Obes Metab. 2011;13: 348-356.

17. Garg R, Chen W, Pendergrass M. Acute pancreatitis in type 2 diabetes treated with exenatide or sitagliptin. Diabetes Care. 2010;33: 2349-2354.

18. Dore DD, Seeger JD, Chan AK. Use of claims-based active drug safety surveillance system to assess the risk of acute pancreatitis with exenatide or sitagliptin compared to metformin or glyburide. Curr Med Res Opin. 2009;25:1019-1027.

19. Nauck MA, Friedrich N. Do GLP-1-based therapies increase cancer risk? Diabetes Care. 2013;36 Suppl 2:S245-S252.

20. Bode B, Stenlöf K, Sullivan D, Fung A, Usiskin K. Efficacy and safety of canagliflozin treatment in older subjects with type 2 diabetes mellitus: a randomized trial. Hosp Pract (1995). 2013;41:72-84.

21. Stenlöf K, Cefalu WT, Kim KA, et al. Efficacy and safety of canagliflozin monotherapy in subjects with type 2 diabetes mellitus inadequately controlled with diet and exercise. Diabetes Obes Metab. 2013;15:372-383.

22. Inagaki N, Kondo K, Yoshinari T, Maruyama N, Sustuta Y, Kuki H. Efficacy and safety of canagliflozin in Japanese patients with type 2 diabetes: a randomized, double blind, placebo-controlled, 12-week study. Diabetes Obes Metab. 2013;15:1136-1145.

23. Pilodori D, Sha S, Mudaliar S, et al. Canagliflozin lowers postprandial glucose and insulin by delaying intestinal glucose absorption in addition to increasing urinary glucose excretion. Diabetes Care. 2013;36: 2154-2161.

24. Nisly SA, Kolanczyk DM, Walton AM. Canagliflozin, a new sodiumglucose cotransporter 2 inhibitor, in the treatment of diabetes. $\mathrm{Am} \mathrm{J}$ Health Syst Pharm. 2013;70:311-319. 
25. Misra M. SGLT2 inhibitors: a promising new therapeutic option for treatment of type 2 diabetes mellitus. J Pharm Pharmacol. 2012;65: 317-327.

26. Burki T. FDA rejects novel diabetes drug over safety fears. Lancet. 2012;379:507.

27. Riser Taylor S, Harris KB. The clinical efficacy and safety of sodium glucose cotransporter- 2 inhibitors in adults with type 2 diabetes mellitus. Pharmacotherapy. 2013;33:984-999.

28. Irons BK, Weis JM, Stapleton MR, Edwards KL. An update in incretinbased therapy: a focus on dipeptidyl peptidase-4 inhibitors. Curr Diabetes Rev. 2012;8:169-182.

29. Karagiannis T, Paschos P, Paletas K, Matthews DR, Tsapas A. Dipeptidyl peptidase-4 inhibitors for treatment of type 2 diabetes mellitus in the clinical setting: systematic review and meta-analysis. $B M J$. 2012;344:e1369.

30. Esposito K, Cozzolino D, Bellastella G, et al. Dipeptidyl peptidase-4 inhibitors and $\mathrm{HbA}_{1 \mathrm{c}}$ target of $<7 \%$ in type 2 diabetes: meta-analysis of randomized controlled trials. Diabetes Obes Metab. 2011;13:594-603.

31. Scirica B, Bhatt D, Braunwald E, et al. Saxagliptin and cardiovascular outcomes in patients with type 2 diabetes mellitus. $N$ Engl J Med. 2013;369:1317-1326.

32. Noel RA, Braun DK, Patterson RE, Bloomgren GL. Increased risk of acute pancreatitis and biliary disease observed in patients with type 2 diabetes. Diabetes Care. 2009;32:834-838.

33. Engel SS, Williams-Herman DE, Golm GT, et al. Sitagliptin: review of preclinical and clinical data regarding incidence of pancreatitis. Int J Clin Pract. 2010;64:984-990.

34. Chaisson JL, Josse RG, Hunt JA, et al. The efficacy of acarbose in the treatment of patients with non-insulin dependent diabetes mellitus Ann Intern Med. 1994;121:928-935.

35. Johnston PS, Lebovitz HE, Conniff RF, Simonson DC, Raskin P, Munera CL. Advantages of $\alpha$-glucosidase inhibition as monotherapy in elderly type 2 diabetic patients. J Clin Endocrinol Metab. 1998;183: 1515-1522.

36. Scott LJ, Spencer CM. Miglitol: a review of its therapeutic potential in type 2 diabetes mellitus. Drugs. 2000;59:521-549.

37. Buse J, Hart K, Minasi LA. The PROTECT study: final results in a large multicenter postmarketing study in patients with type 2 diabetes. Clin Ther. 1998;20:257-269.

38. Takami K, Takeda N, Nakashima K, et al. Effects of dietary treatment alone diet with voglibose or glyburide on abdominal adipose tissue and metabolic abnormalities in patients with newly diagnosed type 2 diabetes. Diabetes Care. 2002;25:658-662.

39. Iwamoto Y, Tajima N, Kadowaki T, et al. Efficacy and safety of sitagliptin monotherapy compared with voglibose in Japanese patients with type 2 diabetes: a randomized, double-blind trial. Diabetes Obes Metab. 2010;12:613-622.

40. Handelsman Y. Role of bile acid sequestrants in the treatment of type 2 diabetes. Diabetes Care. 2011;34 Suppl 2:S244-S250.

41. Smushkin G, Sathananthan M, Piccinini F, et al. The effect of a bile acid sequestrant on glucose metabolism in subjects with type 2 diabetes. Diabetes. 2013;62:1094-1101.

42. Schwartz SL, Lai YL, Xu J, et al. The effect of colesevelam hydrochloride on insulin sensitivity and secretion in patients with type 2 diabetes a pilot study. Metab Syndr Relat Disord. 2010;8:179-187.

43. Fonseca VA, Rosenstock J, Wang AC, Truitt KE, Jones MR. Colesevelam $\mathrm{HCl}$ improves glycemic control and reduces LDL cholesterol in patients with inadequately controlled type 2 diabetes on sulfonylurea-based therapy. Diabetes Care. 2008;31:1479-1484.

44. Goldberg RB, Fonseca VA, Truitt KE, Jones MR. Efficacy and safety of colesevelam in patients with type 2 diabetes mellitus and inadequate glycemic control receiving insulin-based therapy. Arch Intern Med. 2008;168:1531-1540.

45. Rigby S, Handelsman Y, Lai Y, Abby S, Tao B, Jones MR. Effects of colesevelam, rosiglitazone, or sitagliptin on glycemic control and lipid profile in patients with type 2 diabetes mellitus inadequately controlled by metformin monotherapy. Endocr Pract. 2010;16:53-63.
46. Goldfine AB, Fonseca VA, Jones MR, Wang AC, Ford DM, Truitt KE. Long-term safety and tolerability of colesevelam $\mathrm{HCl}$ in subjects with type 2 diabetes. Horm Metab Res. 2010;42:23-3-

47. Bays HE. Long-term (52-78 weeks) treatment with colesevelam $\mathrm{HCl}$ added to metformin therapy in type 2 diabetes mellitus patients. Diabetes Metab Syndr Obes. 2012;5:125-134.

48. Holt RI, BarnettAH, Bailey CJ. Bromocriptine: old drug, new formulation and new indication. Diabetes Obes Metab. 2010;12:1048-1057.

49. DeFronzo RA. Bromocriptine: a sympatholytic, D2-dopamine agonist for the treatment of type 2 diabetes. Diabetes Care. 2011;34:789-794.

50. Pijil H, Ohashi S, Matsuda M, et al. Bromocriptine: a novel approach to the treatment of type 2 diabetes. Diabetes Care. 2000;23: 1154-1161.

51. Scranton R, Cincotta A. Bromocriptine - unique formulation of a dopamine agonist for the treatment of type 2 diabetes. Expert Opin Pharmacother. 2010;11:269-279.

52. Kerr JL, Timpe EM, Petkewicz KA. Bromocriptine mesylate for glycemic management in type 2 diabetes mellitus. Ann Pharmacother. 2010;44:1777-1785.

53. Gaziano JM, Cincotta AH, O'Connor CM, et al. Randomized clinical trial of quick-release bromocriptine among patients with type 2 diabetes on overall safety and cardiovascular outcomes. Diabetes Care. 2010;33: 1503-1508.

54. Gaziano JM, Cincotta AH, Vinik A, Blonde L, Bohannon N, Scranton R. Effect of bromocriptine-QR (a quick-release formulation of bromocriptine mesylate) on major adverse cardiovascular events in type 2 diabetes subjects. J Am Heart Assoc. 2012;1:e002279.

55. Raccah D. Options for the intensification of insulin therapy when basal insulin is not enough in type 2 diabetes mellitus. Diabetes Obes Metab. 2008;10 Suppl 2:76-82.

56. Janka HU, Plewe G, Riddle MC, Kliebe-Frisch C, Schweitzer MA, Yki-Järvinen H. Comparison of basal insulin added to oral agents versus twice-daily premixed insulin as initial insulin therapy for type 2 diabetes. Diabetes Care. 2005;28:254-259.

57. Ryan EA, Imes S, Wallace C. Short-term intensive insulin therapy in newly diagnosed type 2 diabetes. Diabetes Care. 2004;27: 1028-1032.

58. Li Y, Xu W, Liao Z, et al. Induction of long-term glycemic control in newly diagnosed type 2 diabetic patients is associated with improvement of beta-cell function. Diabetes Care. 2004;27:2597-2602.

59. Chen HS, Wu TE, Jap TS, Hsiao LC, Lee SH, Lin HD. Beneficial effects of insulin on glycemic control and beta-cell function in newly diagnosed type 2 diabetes with severe hyperglycemia after short-term intensive insulin therapy. Diabetes Care. 2008;31:1927-1932.

60. Currie CJ, Poole CD, Evans M, Peters JR, Morgan CL. Mortality and other important diabetes-related outcomes with insulin vs other antihyperglycemic therapies in type 2 diabetes. J Clin Endocrinol Metab. 2013;98:668-677.

61. Schernthaner G, Currie CJ, Schernthaner GH. Do we still need pioglitazone for the treatment of type 2 diabetes? A risk-benefit critique in 2013. Diabetes Care. 2013;36 Suppl 2:S155-S161.

62. Pavo I, Jermendy G, Varkonyi TT, et al. Effect of pioglitazone compared with metformin on glycemic control and indicators of insulin sensitivity in recently diagnosed patients with type 2 diabetes. J Clin Endocrinol Metab. 2003;88:1637-1645.

63. Perez-Monteverde A, Seck T, Xu L, et al. Efficacy and safety of sitagliptin and the fixed-dose combination of sitagliptin and metformin vs pioglitazone in drug-naïve patients with type 2 diabetes. Int $J$ Clin Pract. 2011;65:930-938.

64. Wainstein J, Katz L, Engel SS, et al. Initial therapy with the fixed-dose combination of sitagliptin and metformin results in greater improvement in glycaemic control compared with pioglitazone monotherapy in patients with type 2 diabetes. Diabetes Obes Metab. 2012;14: 409-418.

65. Tan MH, Baksi A, Krahulec B, et al. Comparison of pioglitazone and gliclazide in sustaining glycemic control over 2 years in patients with type 2 diabetes. Diabetes Care. 2005;28:544-550. 
66. Dormandy JA, Charbonnel B, Eckland DJ, et al. Secondary prevention of macrovascular events in patients with type 2 diabetes in the PROactive Study. Lancet. 2005;366:1279-1289.

67. Dormuth CR, Carney G, Carleton B, Bassett K, Wright JM. Thiazolidinediones and fractures in men and women. Arch Intern Med. 2009; 169:1395-1402.

68. Idris I, Warren G, Donnelly R. Association between thiazolidinedione treatment and risk of macular edema among patients with type 2 diabetes. Arch Intern Med. 2012;172:1005-1011.

69. Neumann A, Weill A, Ricordeau P, Fagot JP, Alla F, Allemand H. Pioglitazone and risk of bladder cancer among diabetic patients in France: a population-based cohort study. Diabetologia. 2012;55:1953-1962.
70. DeFronzo RA, Eldor R, Abdul-Ghani M. Pathophysiologic approach to therapy in patients with newly diagnosed type 2 diabetes. Diabetes Care. 2013;36 Suppl 2:S127-S138.

71. Glucophage (metformin hydrochloride tablets) FDA-approved label. Available from: http://www.accessdata.fda.gov/drugsatfda_docs/label/ 2008/020357s031,021202s016lbl.pdf. Accessed September 25, 2013.

72. United Kingdom Medicines and Healthcare Products Regulatory Agency. Metformin Summary of Product Characteristics. Available from: http:/www.mhra.gov.uk/home/groups/spcpil/documents/spcpil/ con1376454233492.pdf. Accessed September 25, 2013.

\section{Publish your work in this journal}

Diabetes, Metabolic Syndrome and Obesity: Targets and Therapy is an international, peer-reviewed open-access journal committed to the rapid publication of the latest laboratory and clinical findings in the fields of diabetes, metabolic syndrome and obesity research. Original research, review, case reports, hypothesis formation, expert opinion and commentaries are all considered for publication. The manuscript management system is completely online and includes a very quick and fair peer-review system, which is all easy to use. Visit http://www.dovepress.com/testimonials.php to read real quotes from published authors.

Submit your manuscript here: http://www.dovepress.com/diabetes-metabolic-syndrome-and-obesity-targets-and-therapy-journal 